Rafał Anyszka*, Dariusz M. Bieliński, Zbigniew Pędzich, Magdalena Zarzecka-Napierała, Mateusz Imiela and Przemystaw Rybiński

\title{
Processing and Properties of Fire Resistant EPDM Rubber-Based Ceramifiable Composites
}

DOI 10.1515/htmp-2016-0059

Received March 17, 2016; accepted August 22, 2016

Abstract: Low softening point temperature glassy frit, reinforcing silica, wollastonite and dicumyl peroxide were incorporated into ethylene-propylene-diene (EPDM) rubber matrix in different amounts in order to obtain ceramifiable composites. Kinetics of vulcanization of the mixes was measured. Mechanical properties, micromorphology, thermal properties and combustibility of the vulcanizates were studied as well as compression strength of the ceramic residue obtained after heat treatment. Studies show that optimal amount of glassy frit from the point of view of ceramification effectiveness in dispersed mineral phase is $40 \% \mathrm{wt}$.

Keywords: EPDM rubber, ceramization, ceramification, thermal properties, micromorphology, composites

\section{Introduction}

For many years ceramifiable (ceramizable) composites have been used solely as protective cable covers to ensure the proper working of electrical installation in case of fire [1]. Due to its extraordinary thermal and fire resistance properties, silicone rubber has been used as a continuous phase for ceramifiable composites $[2,3]$.

*Corresponding author: Rafat Anyszka, Faculty of Chemistry, Institute of Polymer and Dye Technology, Lodz University of Technology, Stefanowskiego 12/16, 90-924 Lodz, Poland, E-mail: anyszka.rafal@gmail.com

Dariusz M. Bieliński, Faculty of Chemistry, Institute of Polymer and Dye Technology, Lodz University of Technology, Stefanowskiego 12/16, 90-924 Lodz, Poland

Zbigniew Pędzich, Magdalena Zarzecka-Napierata, Department of Ceramics and Refractory Materials, Faculty of Materials Science \& Ceramics, AGH - University of Science \& Technology, Al.

Mickiewicza 30, 30-045 Krakow, Poland

Mateusz Imiela, Faculty of Chemistry, Institute of Polymer and Dye Technology, Lodz University of Technology, Stefanowskiego 12/16, 90-924 Lodz, Poland

Przemystaw Rybiński, The Jan Kochanowski University, Management of Environment Protection and Modeling, Żeromskiego 5, 25-369 Kielce, Poland
However, the principal reason for using silicone polymers as a matrix for ceramifiable composites is their ability to create inorganic silica during combustion in the presence of oxygen. The silica formed after thermo-oxidative decomposition of silicone rubber reacts with other mineral compounds such as calcium oxide producing wollastonite which in turn increases the mechanical endurance of the char produced after combustion of the composite by creating needle-shape crystals. This reaction was adapted by Gardelle B. et al. for developing silicone-based coatings to protect steel against severe, cellulosic fire [4]. The silica created during thermo-oxidative degradation of silicone rubber can also sinter on an active surface of different mineral fillers in form of amorphous brittle phase sticking particles of different minerals together. This phenomenon was described by Hanu L. G. et al., who studied thermal properties of silicone rubber filled with muscovite mica of different particle sizes. They proved that the mechanical endurance of ceramic structure obtained after ceramification depends strongly on the average particle size of mica [5]. Furthermore, Hanu L. G. et al. proposed incorporation of low melting point temperature amorphous glass powder into a silicone matrix to enhance mechanical properties of the ceramic residue formed in fire [6].

However, as organic polymers do not create inorganic products of thermo-oxidative decomposition, the development of organic polymer-based ceramifiable composites requires the presence of low melting point ceramic additives that stick the particles of thermally resistant mineral fillers together. Most often, amorphous ceramic oxide frits act as fluxing agent creating a robust ceramic structure after exposing the ceramifiable composite to fire. The melting point of such functional fillers ranges from $500-700^{\circ} \mathrm{C}$. This is a relatively high value, far higher than the average decomposition temperature of most polymers. In our previous work, we successfully used boron oxide at a melting point temperature of $450^{\circ} \mathrm{C}$, as a fluxing agent for ceramifiable composites $[7,8]$. However, its acidic character and hydrophilicity could cause processing problems.

The high flammability of unfilled organic polymers has made the development of new kinds of flame-retardant 
systems a very popular area of research [9, 10]. The ceramification process has been also adapted for these purposes, Shao H. et al., developed and studied the properties of polyethylene-based ceramifiable composites [11], while Al-Hassany Z. et al. developed and described poly(vinyl acetate) ceramifiable composites intended for sealant applications [12]. Recent studies in the field of ceramifiable organic rubber based composites has put emphasis on utilization of poly(ethylenevinyl acetete) copolymer [13] and its blend with PDMS [14] as a continuous phase. In this paper, we present the properties of ethylene-propylene-diene (EPDM) rubberbased ceramifiable composites.

\section{Experimental section}

\section{Materials}

Ethylene-propylene-diene rubber (EPDM) "Keltan 21" (Mooney viscosity in $125^{\circ} \mathrm{C}-25$, ethylene content - 60\%) was purchased from Lanxess AG (Germany). The reinforcing filler - precipitated silica "Arsil" (bulk density $150 \mathrm{~g} / \mathrm{cm}^{3}$ ) was obtained form Rudniki S. A. (Poland). Reference mineral filler - wollastonite "Termin 939-304" (L/D - 8/1, hardness - 4.5 Mohs, density - $2.85 \mathrm{~g} / \mathrm{cm}^{3}$ ) was obtained from Quarzwerke $\mathrm{GmbH}$ (Germany). The curing agent - dicumyl peroxide (DCP) (purity - 98\%) was purchased from Sigma-Aldrich (USA). The glassy frit used as a fluxing agent - "FR-2030" (composed of $13.7 \mathrm{wt} \% \mathrm{Na}_{2} \mathrm{O}, 2.0$ wt $\% \mathrm{BaO}, 23.5$ wt $\% \mathrm{ZnO}, 2.0$ wt $\% \mathrm{Al}_{2} \mathrm{O}_{3}$, 43.1 wt $\% \mathrm{SiO}_{2}$, 15.7 wt $\% \mathrm{~B}_{2} \mathrm{O}_{3}$ ) was obtained from Reimbold \& Strick $\mathrm{GmbH}$ (Germany).

\section{Methods}

EPDM rubber mixes were prepared by two roll (diameter $150 \mathrm{~mm}$, length - $200 \mathrm{~mm}$ ) mill (Bridge, UK) which operates with friction of 1.1. For the composition of mixes, see Table 1. The crucial parameter which distinguishes the mixes is the content of the fluxing agent. Each mix was filled with 300 weight parts of mineral fillers per 100 weight parts of rubber, but the content of the fluxing agent amounts to 30, 40 and 50\% wt of summary fillers weight, in EPDM_30,EPDM_40 and EPDM_50 respectively. Kinetics of vulcanization of prepared mixes was measured by means of Metalchem MW-05 vulcameter (Poland) in
Table 1: Compositions of mixes studied.

\begin{tabular}{lrrrr}
\hline Composition (phr) & & & \multicolumn{2}{c}{ Mix designation } \\
\cline { 2 - 5 } & EPDM_30 & EPDM_40 & EPDM_50 & EPDM_prist \\
\hline EPDM rubber & 100 & 100 & 100 & 100 \\
Reinforcing silica & 105 & 90 & 75 & - \\
Reference filler & 105 & 90 & 75 & - \\
Fluxing agent & 90 & 120 & 150 & - \\
Dicumyl peroxide & 2 & 2 & 2 & 2 \\
\hline
\end{tabular}

$150^{\circ} \mathrm{C}$. Samples of vulcanized rubber were prepared in a heated mold press accordingly to the kinetic of their vulcanization under pressure of $10 \mathrm{MPa}$. Samples for tests were shaped using a mechanical punch press. Micromorphology of vulcanized composites was pictured by means of Molecular Imaging Metrology MI 2000 atomic force microscope (AFM) (USA), working in an oscillating mode with frequency of ca. $170 \mathrm{kHz}$. Mechanical tests were performed by means of Zwick 1435 device (Germany) accordingly to the ISO 37:1998 standard. Thermal stability of the samples was studied by means of Netzsch 449 F3 TG-DTA instrument (Germany), operating with heating speed of $10^{\circ} \mathrm{C} / \mathrm{min}$, under air atmosphere from room temperature to $1,000^{\circ} \mathrm{C}$. Combustibility of the samples was tested by means of a cone calorimeter produced by Fire Testing Technology Ltd. (UK). Square shaped vulcanizates $((100 \times 100) \pm 1 \mathrm{~mm})$ of $2.0 \pm 0.5 \mathrm{~mm}$ thick were heated by $35 \mathrm{~kW} / \mathrm{m}^{2}$ radiant flux. The ceramification ability of samples was investigated by heat treatment in a laboratory furnace. Samples were heated in two different conditions slow heating from room temperature to $800^{\circ} \mathrm{C}$ or $1,000^{\circ} \mathrm{C}$ with heating speed of ca. $8^{\circ} \mathrm{C} / \mathrm{min}$ and fast heat treatment in which samples were placed in a preheated furnace chamber $\left(800^{\circ} \mathrm{C}\right.$ or $\left.1,000^{\circ} \mathrm{C}\right)$. Resistance against fragmentation of ceramic char created after heat treatment of the samples was measured by means of Zwick/Roell Z 2.5 tester (Germany).

\section{Results and discussion}

\section{Kinetics of vulcanization}

Scorch time of the mixes vary from 2.7 to $3.4 \mathrm{~min}$ and its change is not directly connected to the amount of the fluxing agent, whereas vulcanization time slightly increases from 36.1 to $38.2 \mathrm{~min}$, with an increase of 
Table 2: Parameters of kinetics of vulcanization: scorch time (t02), vulcanization time (T90), minimal (Mmin), optimal (Mopt) and maximal (Mmax) torque value and increase of torque $(\Delta M)$.

\begin{tabular}{lrrrr}
\hline $\begin{array}{l}\text { Vulcanization } \\
\text { parameter }\end{array}$ & & & \multicolumn{2}{c}{ Mix designation } \\
\cline { 2 - 5 } & EPDM_30 & EPDM_40 & EPDM _50 & EPDM_prist \\
\hline$\tau_{02}$ (min.) & 2.7 & 3.4 & 3.2 & 2.6 \\
$\tau_{90}(\min )$. & 36.1 & 37.1 & 38.2 & 47.7 \\
$M_{\min }(\mathrm{dNm})$ & 139.1 & 108.7 & 87.1 & 13.1 \\
$M_{\text {opt }}(\mathrm{dNm})$ & 243.3 & 240.4 & 225.4 & 83.7 \\
$M_{\max }(\mathrm{dNm})$ & 254.9 & 255.0 & 240.8 & 106.1 \\
$\Delta M(\mathrm{dNm})$ & 115.8 & 146.3 & 153.7 & 93.0 \\
\hline
\end{tabular}

fluxing agent content, what shows that its presence affects the curing process (Table 2). Generally, all torque values decline significantly with a decrease of silica content what was expected as the precipitated silica is an effective reinforcing filler. However, the torque growth decreases visibly with the increase of silica content, what means that the curing process is less efficient. It could be an effect of a relatively high amount of moisture adsorbed on the surface of silica particles. This may create a favorable environment for acidic impurities leading to the disruption or even prevention of peroxide curing [15-17]. The vulcanization time of EPDM rubber shortens with the addition of each mineral composition.
Table 3: Mechanical parameters of vulcanized samples: tear resistance (TES), tensile strength (TS) and elongation at break (EB).

\begin{tabular}{|c|c|c|c|c|}
\hline \multirow{2}{*}{$\begin{array}{l}\text { Mechanical } \\
\text { parameter }\end{array}$} & \multicolumn{4}{|c|}{ Sample designation } \\
\hline & EPDM _30 & EPDM _40 & EPDM_50 & EPDM _prist \\
\hline TES (N/mm) & 8.8 & 11.1 & 11.6 & 1.0 \\
\hline TS (MPa) & 5.2 & 5.3 & 5.5 & 1.4 \\
\hline EB (\%) & 25 & 90 & 164 & 177 \\
\hline
\end{tabular}

\section{Mechanical properties}

The values of all mechanical parameters increase with the amount of the fluxing agent (Table 3). This seems to be not due to the effect of good reinforcing properties of the fluxing agent rather than of reinforcing silica overload and higher effectiveness of curing of mixes containing lower amounts of silica. On the whole, the mechanical properties of all samples are sufficient for technological applications increasing the tensile strength and tear resistance of EPDM rubber with a slight decrease in its elasticity.

\section{Micromorphology}

AFM picture of EPDM_40 sample surface shows accurately the micro-morphological character of the composites studied (Figure 1). The high amount of mineral


Figure 1: AFM photographs of EPDM_40 surface micromorphology, taken in two different magnifications $(1,2)$ from topography channel (A), amplitude channel (B) and phase channel (C). 
fillers is clearly visible. Wollastonite and the fluxing agent occur in form of relatively big primary particles, whereas silica creates aggregates and agglomerates in an EPDM matrix due to great difference between polar character of silica surface and non-polar aliphatic polymer matrix. Wollastonite is present in the form of needleshape particles (see the down right corner of photo 1), whereas the fluxing agent, as an amorphous milled matter, occurs in the form of irregular-shaped particles.

\section{Thermal stability}

EPDM_40 sample presents the best thermal stability (Table 4). The onset temperature of rapid decomposition of this sample is higher than for EPDM_50, however it equals EPDM_30. It is very likely that the higher amount of reinforcing silica added to EPDM rubber in EPDM_30 and EDPM_40 samples caused the creation of higher amount of

Table 4: Parameters of thermal decomposition of samples studied: onset temperature of changes in kinetics of decomposition $\left(\mathrm{O}_{\mathrm{T}}\right)$, partial mass loss $\left(M_{\perp}\right)$, summary mass loss $\left(S M_{\perp}\right)$, temperature of maximal DTA peaks ( $\left.\mathrm{T}_{\mathrm{DTA}}\right)$ and amount of residue in $1,000^{\circ} \mathrm{C}(\mathrm{PC})$.

\begin{tabular}{lrrrrr}
\hline Sample & $\mathbf{0}_{\mathrm{T}}\left({ }^{\circ} \mathrm{C}\right)$ & $\mathbf{M}_{\mathbf{L}}(\%)$ & $\mathbf{S M}_{\mathbf{L}}(\%)$ & $\mathrm{T}_{\mathrm{DTA}}\left({ }^{\circ} \mathrm{C}\right)$ & $\mathbf{P c}(\%)$ \\
\hline EPDM_50 & 205 & 3.5 & 3.5 & 429 & 70.6 \\
& 428 & 15.9 & 19.4 & 513 & \\
& 545 & 9.7 & 29.1 & & \\
EPDM_40 & 228 & 1.8 & 1.8 & 403 & 71.8 \\
& 430 & 16.0 & 17.8 & 528 & \\
& 595 & 10.1 & 27.9 & & \\
EPDM_30 & 228 & 3.0 & 3.0 & 430 & 71.0 \\
& 430 & 15.8 & 18.8 & 525 & \\
& 580 & 9.8 & 28.6 & & \\
EPDM_prist & 232 & $<1.0$ & $<1.0$ & 261 & 0.0 \\
& 397 & 10.6 & 10.6 & 452 & \\
& 485 & 86.2 & 96.8 & 481 & \\
\hline
\end{tabular}

bound rubber adsorbed on silica surface, which has been proved to be thermally more stable than unbounded rubber [18]. The amount of ceramic char residue after TG test is the highest for EPDM_40 and the kinetics of its decomposition is the slowest (Figure 2). All samples show a characteristic, wide, exothermic DTA signal with a double maximum peak preceded by endothermic signal of moisture evaporation (Figure 3). EPDM_40 shows the lowest value of peaks and the lowest temperature of first peak, whereas EPDM_50 presents exothermic signal of the smallest width. The samples after laboratory furnace heat test do not keep the same

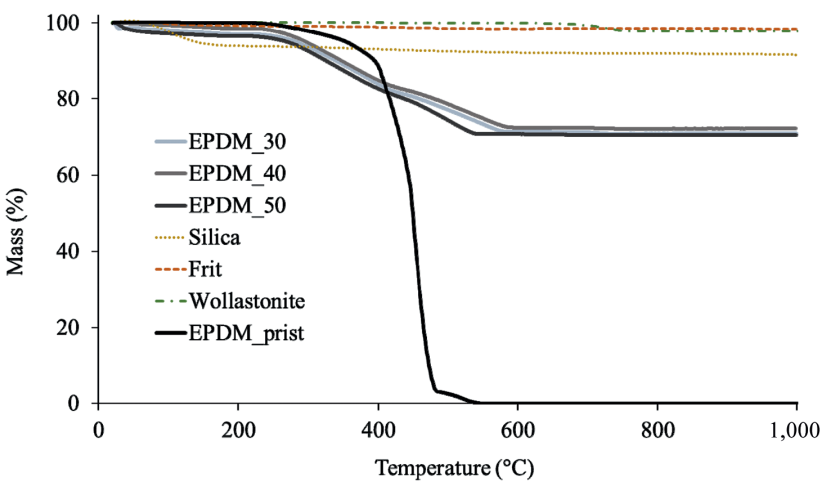

Figure 2: TG curves of samples studied.

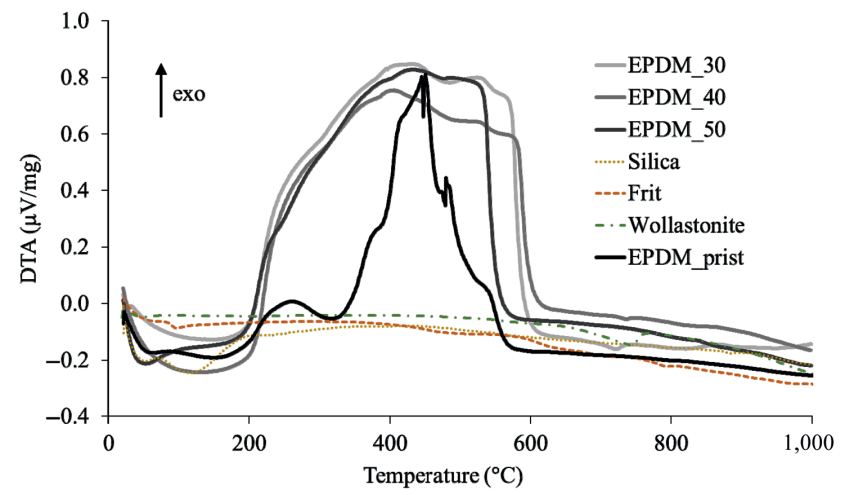

Figure 3: DTA curves of samples studied.

shape, however they maintain a consistent porous structure exhibiting protective properties (Table 5). The force required to crush the ceramic residue is not directly comparable for the samples because their shape was slightly different. However the mechanical resistance of samples after treatment in $800^{\circ} \mathrm{C}$ is much higher than the standard char obtained after heating of common polymer composites. After $1,000^{\circ} \mathrm{C}$ treatment only the EPDM_40 sample was able to create a strong ceramic residue, in fact much

Table 5: Force required to crush ceramic residue created after heat treatment of samples studied.

\begin{tabular}{lrrr}
\hline Mechanical parameter & \multicolumn{3}{c}{ Sample designation } \\
\cline { 2 - 4 } & EPDM_30 & EPDM _40 & EPDM_50 \\
\hline 800 fast (N) & 18.5 & 46.5 & 16.1 \\
800 slow (N) & 42.2 & 9.2 & 40.4 \\
1,000 fast $(\mathrm{N})$ & blown & 77.4 & melted \\
1,000 slow (N) & to weak & 480.0 & melted \\
\hline
\end{tabular}


stronger that after heating up to $800^{\circ} \mathrm{C}$, regardless of heating rate. The strongest ceramic structure was created after slow heating of EPDM_40 up to $1,000^{\circ} \mathrm{C}$. It is very probable that in such temperature very low viscosity of the fluxing agent enhances the stickiness of mineral particles leading to a significant increase of mechanical endurance of the sample. A very high amount of the fluxing agent in EPDM_50 composite causes melting and deformation of the samples after heat treatment in $1,000^{\circ} \mathrm{C}$, whereas a low content of the fluxing agent in EPDM_30 causes blowing of the sample due to rapid decomposition of EPDM rubber matrix or leads to the creation of a very weak ceramic structure. This data correspond precisely to the TG analysis which shows that EPDM_40 exhibits the slowest decomposition rate and produces the highest amount of ceramic residue. The reference sample (EPDM_prist) also decomposes in a three-step process. However, the onset temperatures of each step are shifted into lower values. This indicates that the used filler systems increase the thermal stability of EPDM rubber.

\section{Combustibility}

The most important parameters describing resistance to combustion of a composite material are time to ignition $\left(t_{i}\right)$, peak of heat release rate $\left(\mathrm{HRR}_{\mathrm{p}}\right)$ and total heat release (THR) (Table 6, Figures 4-7). Taking into account the first two of them the EPDM_30 composite exhibits outstanding properties. Its time to ignition is almost 50 $\mathrm{s}$ higher than that of all other samples and heat release rate peak is the lowest. It is highly likely that the large amount of silica provides high thermal stability as the

Table 6: Combustibility parameters of samples studied: time to ignition (ti), time to flameout (to), total heat release (THR), mass loss $(\mathrm{ml})$, heat release rate peak (HRRp) and its mean value (HRRm), effective heat of combustion peak (EHCP) and its mean value $(\mathrm{EHCm})$, mass loss rate peak (MLRp) and its mean value (MLRm).

\begin{tabular}{lrrrr}
\hline Parameter & \multicolumn{4}{c}{ Sample description } \\
\cline { 2 - 5 } & EPDM_30 & EPDM_40 & EPDM_50 & EPDM_prist \\
\hline $\mathrm{t}_{\mathrm{i}}(\mathrm{s})$ & 121 & 74 & 72 & 77 \\
$\mathrm{t}_{\mathrm{o}}(\mathrm{s})$ & 473 & 439 & 498 & 590 \\
$\mathrm{THR}\left(\mathrm{MJ} / \mathrm{m}^{2}\right)$ & 21.6 & 19.9 & 29.9 & 32.3 \\
$\mathrm{~m}_{\mathrm{l}}(\%)$ & 28.1 & 27.9 & 28.5 & 81.8 \\
$\mathrm{HRR}_{\mathrm{p}}(\mathrm{kW} / \mathrm{m})$ & 113.1 & 123.2 & 148.3 & 276.5 \\
$\mathrm{HRR}_{\mathrm{m}}(\mathrm{kW} / \mathrm{m})$ & 62.1 & 53.7 & 70.7 & 61.3 \\
$\mathrm{EHC}_{\mathrm{p}}(\mathrm{MJ} / \mathrm{kg})$ & 74.0 & 71.8 & 65.0 & 71.1 \\
$\operatorname{EHC}_{\mathrm{m}}(\mathrm{MJ} / \mathrm{kg})$ & 25.1 & 18.1 & 27.4 & 18.6 \\
$\operatorname{MLR}_{\mathrm{p}}(\mathrm{g} / \mathrm{s})$ & 0.079 & 0.087 & 0.081 & 0.188 \\
$\operatorname{MLR}_{\mathrm{m}}(\mathrm{g} / \mathrm{s})$ & 0.022 & 0.026 & 0.023 & 0.029 \\
\hline
\end{tabular}

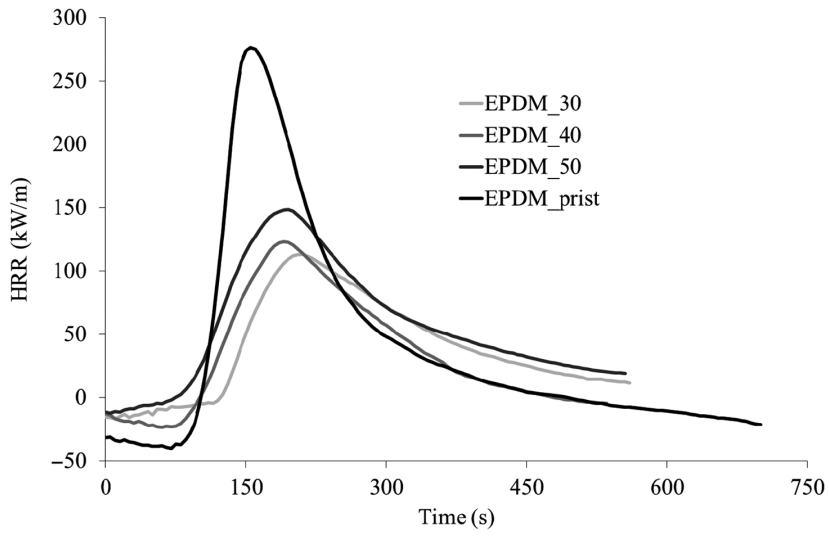

Figure 4: Heat release rate (HRR) curves of samples studied.

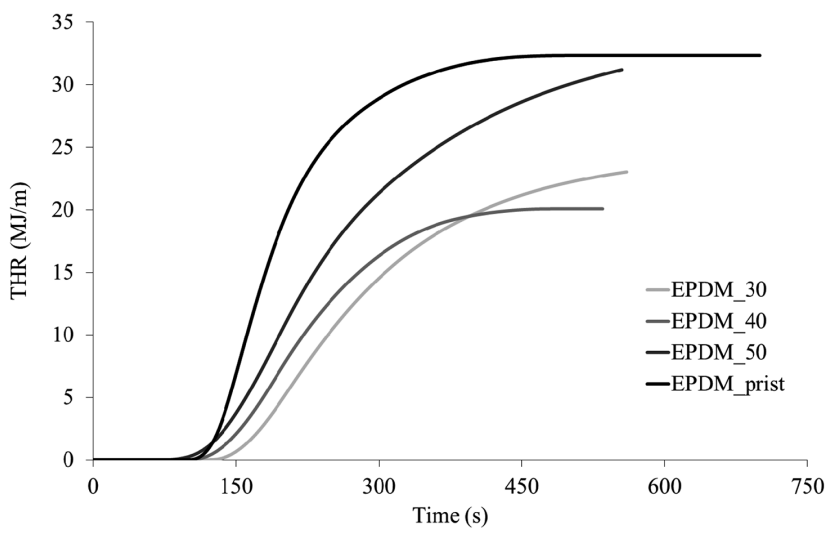

Figure 5: Total heat release (THR) curves of samples studied.



Figure 6: Averaged heat release rate (ARHE) curves of samples studied.

TG/DTA analysis showed but it also contains the highest amount of water which evaporates suppressing the temperature of the composite surface during the cone calorimetry test. 


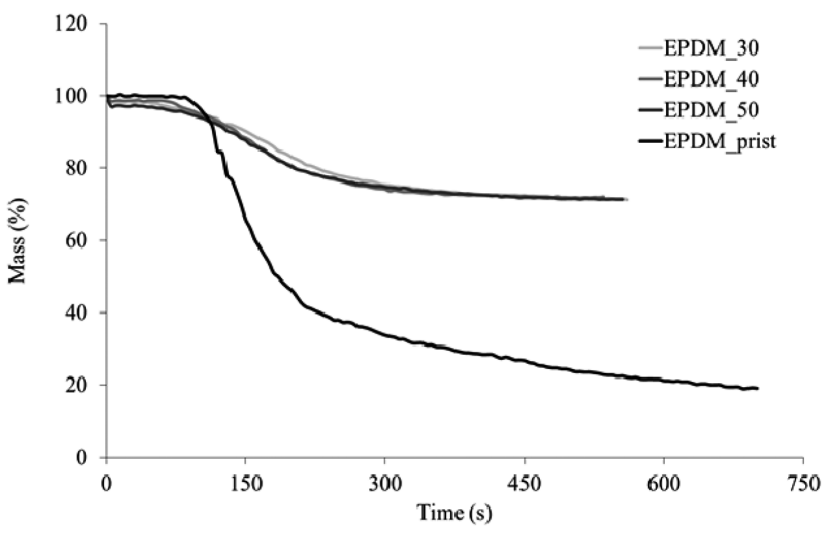

Figure 7: Mass loss curves of samples studied.

The EPDM_40 composite, which showed the best ceramifiable and thermal properties exhibits also low combustibility having the lowest total heat release parameter. This is probably the result of an effective ceramification on the surface of the composite leading to the production of dense and barrier ceramic char and preventing combustible volatiles from escaping and burning in the fire zone (Figure 8).

\section{Summary}

In this paper, properties of EPDM rubber-based ceramifiable composites filled with different mixes of mineral powders are presented. Cross-linking efficiency of the mixes studied improves with a decrease of reinforcing silica content. The mechanical properties of vulcanized samples are also better in the composites with a lower amount of silica. Non-homogenous micromorphology of the composites is exemplified with EPDM_40 sample by means of AFM microscope. Thermal analysis and thermal treatment of the samples studied show that the addition of $40 \%$ of fluxing agent to the dispersed phase ensures an optimal ceramification performance, thermal stability and combustibility of EPDM rubberbased composites.

Acknowledgements: Sincere thanks to Martyna Kościukiewicz for providing language help: https://pl.lin kedin.com/pub/martyna-kościukiewicz/108/456/76b/pl.

Funding: This research was supported by the Young Scientists' Fund at the Faculty of Chemistry, Lodz University of Technology, Grant No: W-3D/FMN/32G/2016.
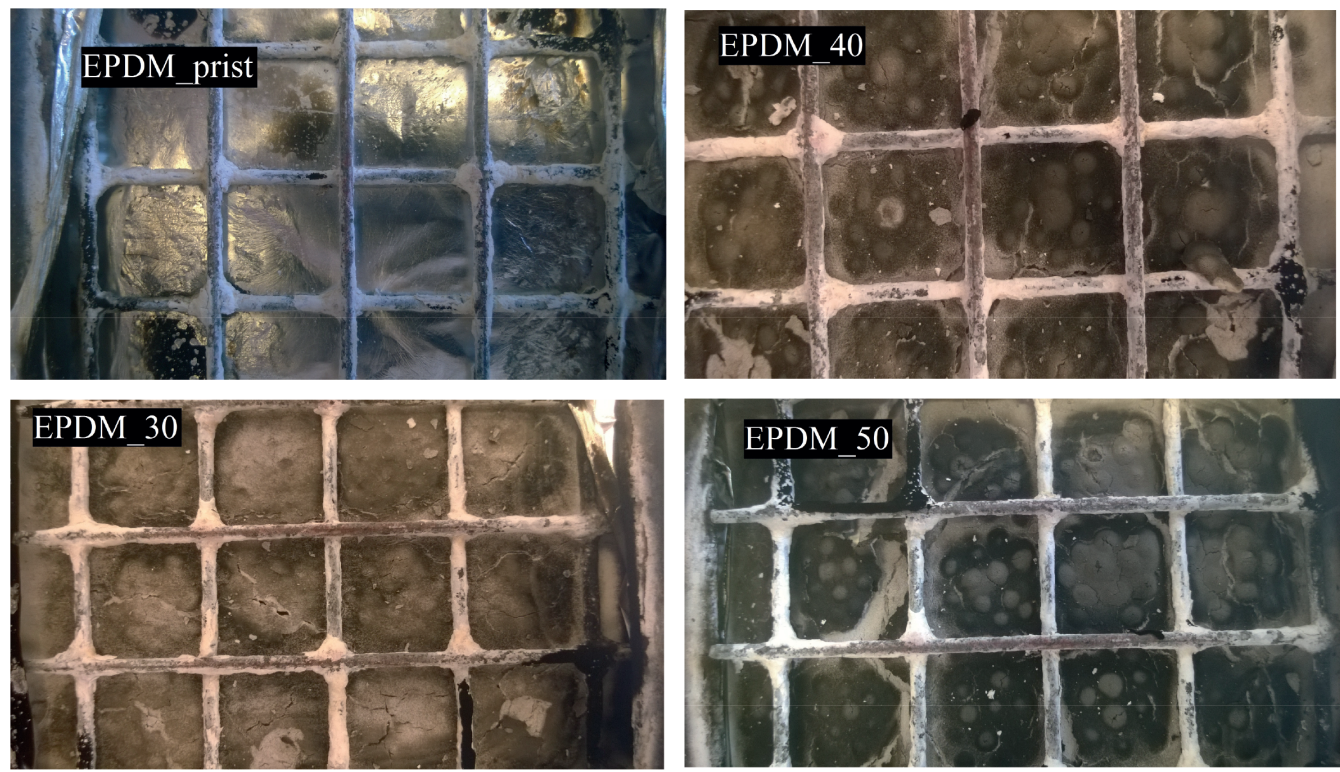

Figure 8: Photographs of samples studied residue after cone calorimetry test. 


\section{References}

[1] C. Henrist, A. Rulmont, R. Cloots, B. Gilbert, A. Bernard and G. Beyer, Mater. Lett., 46 (2005) 5741-5749.

[2] S. Hamdani, C. Longuet, D. Perrin, J.-M. Lopez-Cuesta and F. Ganachaud, Polym. Degrad. Stabil., 94 (2009) 465-495.

[3] M. Imiela, R. Anyszka, D.M. Bieliński, Z. Pędzich, M. ZarzeckaNapierata and M. Szumera, J. Therm. Anal. Calorim., 124 (2016) 197-203.

[4] B. Gardelle, S. Duquesne, P. Vandereecken and S. Bourbigot, J. Fire Sci., 32 (2014) 374-387.

[5] L.G. Hanu, G.P. Simon and Y.B. Cheng, Mater. Sci. Eng. A, 398 (2005) 180-187.

[6] L.G. Hanu, G.P. Simon, J. Mansouri, R.P. Burford and Y.B. Cheng, J. Mater. Process. Technol., 153-154 (2004) 401-407.

[7] R. Anyszka, D.M. Bieliński and M. Jędrzejczyk, Appl. Spectrosc., 67 (2013) 1437-1440.

[8] R. Anyszka, D.M. Bieliński, Z. Pędzich and M. Szumera, J. Therm. Anal. Calorim., 119 (2015) 111-121.
[9] P. Rybiński, G. Janowska, M. Jóźwiak and A. Pająk, J. Therm. Anal. Calorim., 107 (2012) 1219-1224.

[10] P. Rybiński, G. Janowska, M. Jóźwiak and A. Pająk, J. Therm. Anal. Calorim., 109 (2012) 561-571.

[11] H. Shao, T. Wang and Q. Zhang, Adv. Comp. Lett., 19 (2010) 175-179.

[12] Z. Al-Hassany, A. Genovese and R.A. Shanks, Express Polym. Lett., 4 (2010) 79-93.

[13] H.-W. Di, C. Deng, R.-M. Li, L.-P. Dong and Y.-Z. Wang, RSC Adv., 5 (2015) 51248-51257.

[14] E.E. Ferg, S.P. Hlangothi and S. Bambalaza, Polym. Composite (2015) Doi:10.1002/pc.23595

[15] S.D. Ogunniyi, Prog. Rubber. Plast. Technol., 15 (1999) 95-112.

[16] J. Heiner, B. Stenberg and M. Persson, Polym. Test., 22 (2003) 253-257.

[17] R. Anyszka, D.M. Bieliński and M. Kowalczyk, Elastomery, 17 (2013) 16-20. in polish.

[18] M. Anggaravidya, S. Sudirman, B. Soegijo, E. Budianto and M. Djamin, Adv. Mater. Res., 626 (2013) 114-120. 